\title{
Population ageing dynamics in the North Atlantic region of the Arctic
}

\author{
Anastasia Emelyanova and Arja Rautio*
}

\begin{abstract}
This paper contributes to our understanding of the demographic developments and the transition to older age structures in the sparsely populated Arctic region: in Iceland and in the two Danish autonomous territories of the Faroe Islands and Greenland. We compare the population ageing dynamics of the region with those of mainland Denmark for the 1980-2015 period. We also examine whether population ageing has been developing differently in the communities of the North than in Denmark, and shed light on the question of whether a regionally specific policy approach to population ageing is required. In our study, ageing is measured by applying a dual methodology. The two sets of indicators are based on calculations of "chronological" and "prospective" ages. The latter is an innovative approach developed by Sanderson and Scherbov (2008) that considers improvements in life expectancy over time. Our results show that the size of the North Atlantic region's older population is well below the Danish national average. According to chronological indicators, the ageing rates have been rising in recent years. Prospective indicators, which take into account changes in population longevity, also provide information about competing trends in population rejuvenation. In addition, the prospective approach reveals a cross-territorial convergence in recent decades, as well as a slower pace of ageing that can be accounted for in policy planning.
\end{abstract}

\footnotetext{
* Anastasia Emelyanova (corresponding author), International Institute for Applied Systems Analysis (IIASA), Laxenburg, Austria Email: emelyan@iiasa.ac.at

Arja Rautio, Centre for Arctic Medicine, Thule Institute, University of Oulu, Finland Email: arja.rautio@oulu.fi
} 


\section{Introduction}

\subsection{Study aims}

The dynamics of "getting older" are central to "every single aspect of planning at every single imaginable level: from the individual to the workplace to the societal to the global levels" (Leeson 2002, 5). Indeed, the phenomenon of population ageing, which is currently taking place almost everywhere in the world, is unfolding on a scale hitherto unseen in human history. The question of how societies should deal with population ageing has sparked heated debates across political and scientific forums, especially in countries where life expectancy is very high, and the population has reached its highest-ever point in terms of maturity (World Health Organization 2011). At the same time, in the existing research, ageing that occurs at a subnational and at smaller territorial levels has received considerably less attention than ageing in major world regions and across countries.

Past research has shown that the rate of population ageing observed within remote communities of the Arctic region differs, sometimes significantly, from the average rates of the countries to which those communities belong, and from the rates of the southern territories of Arctic countries. This pattern has been observed in various parts of the Arctic, such as in the Barents Euro-Arctic region (Danilova et al. 2011; Nummela et al. 2011; Emelyanova and Rautio 2012; Emelyanova and Rautio 2016), the Russian North (Danilova and Golubeva 2011; Emelyanova and Rautio 2013), the Nordic region (Nordregio publications, cited below), the North American Arctic (Moore and Pacey 2004; Hamilton and Mitiguy 2009; Wilson et al. 2012; Lewis 2013), and across the Arctic as a whole (Larsen and Fondahl 2014; Emelyanova 2015). These authors have generally found that the ageing process in the sparsely populated communities of the Arctic can transform those communities at every level, and can profoundly distort the age composition of local populations. Subnationallevel data from these studies suggest that policy action on ageing that takes into account the particular characteristics of the North is needed, and that modifications of policy action at the national level may be required if cross-territorial differences are found to be substantial.

The North Atlantic region of the Arctic includes Iceland and two autonomous territories of Denmark: namely, the Faroe Islands and Greenland (Figure 1). These areas have many common features. For example, all of these areas have (i) a closed geographical location, (ii) a high degree of peripherality and isolation, (iii) geopolitical status as part of Europe, (iv) an egalitarian social structure, (v) a parliamentary system of government, (vi) a small domestic market with fishing being a predominant source of income, and (vii) a population living in either relatively small urban centres or remote settlements. There is something of a gap in the demographic literature on this part of the Arctic, especially with regard to the ageing of its population. We aim to fill this gap with this study.

Several papers published in English have contributed to our understanding of the demography of coastal societies of the North Atlantic (Foss and Juvkam 2005; 


\section{Figure 1:}

The area of the study: North Atlantic, including Iceland, Greenland, and the Faroe Islands

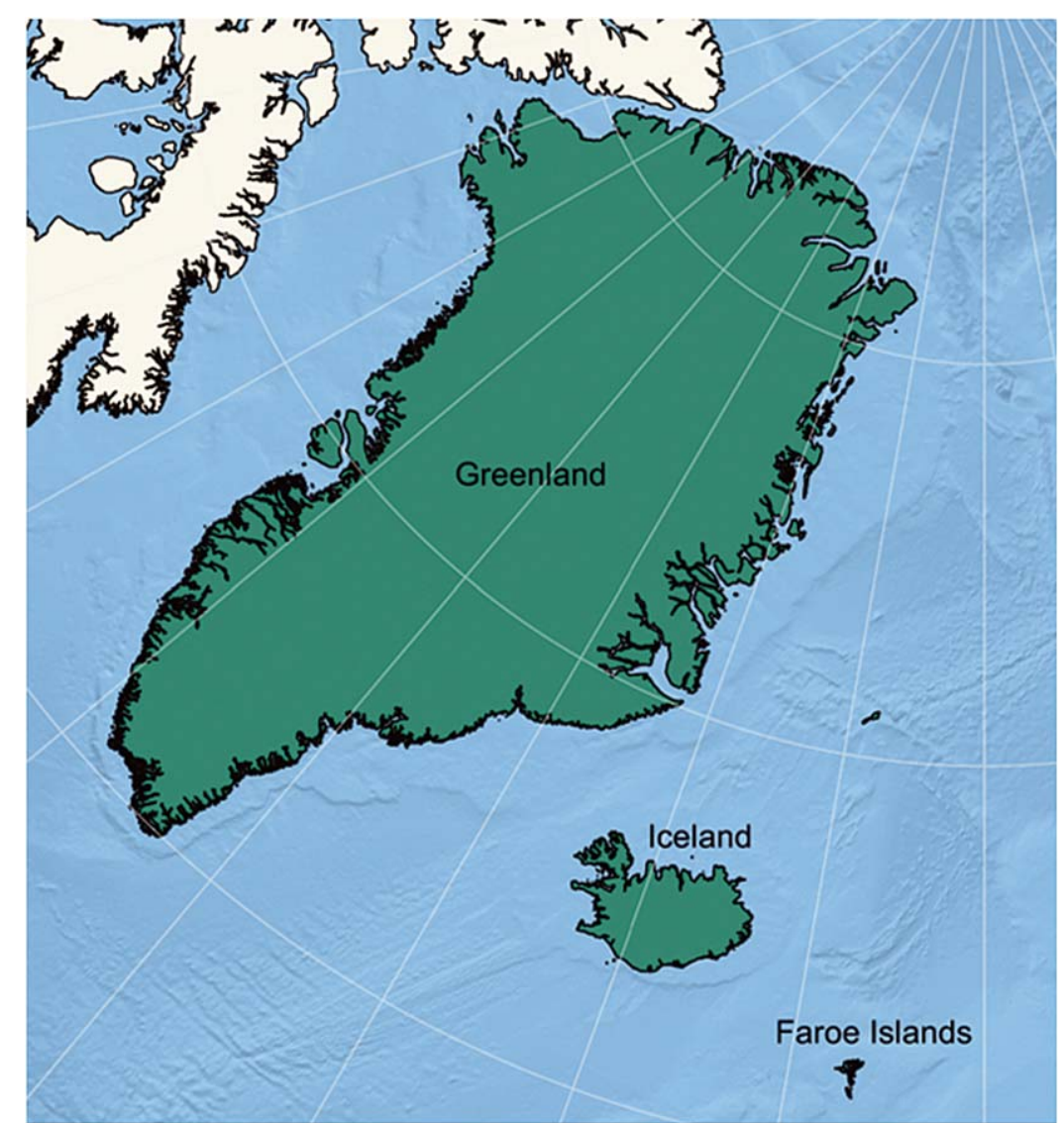

Source: The North Atlantic Marine Mammal Commission, http://www.nammco.no/.

Gløersen 2005; Rauhut et al. 2008; Hansen et al. 2011; Rasmussen 2011; Hansen et al. 2012b; Hörnström and Roto 2013, Roto et al. 2014, Roto and Rasmussen 2016). However, relatively few of these papers have addressed the issue of societal ageing, even though population ageing, along with urbanisation, are among the most pronounced demographic trends of recent years.

According to the sources cited above, the demographics of the North Atlantic region have changed dramatically over the past 40 years. Migration has been a strong driver of this change, with many consequences for the age structures of small communities. Currently, as in the past, large-scale industrial projects and recurrent financial crises in the region are triggering waves of migration. For instance, the 
main demographic crisis in the Faroe Islands is related to changes in the fisheries sector. While the sector was successful in the 1970s, it experienced a collapse associated with overfishing in the 1990s, which in turn led to overinvestment, unemployment, and out-migration. As a result of heavy emigration between 1989 and 1994, the population of the Faroe Islands declined by $10 \%$. Since the 2000s, positive economic changes have stabilised migration. In the case of Greenland, the island moved from Danish colonial status to Home Rule in 1979. This new status led to a large wave of out-migration, and the emigration rate of native Greenlanders did not decrease until more attractive workplaces were established and investments in education were made in the territory. Thousands of people emigrated from Iceland in 2008-2009 in the wake of the financial collapse of 2008; this was the largest wave of migration from Iceland since 1887.

These historical events have caused the populations of the North Atlantic region to age rapidly. Although the region still has higher birth rates than most European countries, emigration rates have been especially high among people of reproductive ages. The older population has risen most sharply in Iceland and in Greenland, where the age structures had been young, but changed due to significant outflows of people of childbearing age, and particularly of young women pursuing educational and career opportunities elsewhere. As these trends have distorted the birth-death balance, societal ageing has become particularly intense in remote coastal areas of the North Atlantic.

In light of these developments, the aim of this paper is to construct a comprehensive cross-regional profile of demographic ageing in the North Atlantic for the 1980-2015 period using the available background data. We identify the major demographic events that have been contributing to the shift towards the ageing of the North Atlantic populations. In addition to using the traditional approach to measuring ageing, we are rethinking ageing trends, and thus apply a new "prospective" methodology. This approach allows us (i) to identify the oldest and the youngest areas in the region, as well as the areas that are ageing the fastest and the slowest (or that are, by contrast, rejuvenating); (ii) to compare the ageing rates of the Danish autonomous territories to those of mainland Denmark; and, finally, (iii) to examine whether the ageing trends are converging or diverging across the countries and territories of the North Atlantic. The analysis will be of interest to demographers, social scientists, and policy planners. Appendix 1 summarises the ageing rates for the North Atlantic and Denmark for both sexes for the period under study.

\subsection{Methods}

In this study, we measure population ageing by applying a dual methodology, and compare the results of the traditional and the new "prospective" approaches to measuring ageing. The main difference between the two methodologies is the age on which these measures are based: the chronological age or the prospective age. 
The traditional indicators of population ageing include the median age (MA), the share of people over the age of 60 (Prop 60+), the ageing index (AI), and the oldage dependency ratio (OADR) (e.g., monitored in United Nations 2015). The MA is represented by a line drawn to numerically divide the population into two equal parts: one older and one younger than the age at the dividing line. The Prop 60+ relates the population aged 60 and older to the total population. The AI refers to the percentage of people aged 60 and older divided by the number of children aged zero to 14 . The OADR relates the number of people aged 60 and older to the number of people aged 15 to 59 .

These indicators are based on chronological age; that is, on the number of years already lived. As these indicators are monitored internationally and are cited in most studies on societal ageing, they allow researchers to make broad regional and even global comparisons of ageing trends. The computation techniques used to construct these indicators are relatively simple, as they involve subdividing population statistics by age and sex. In this text, we refer to results related to these indices as having been measured in a "traditional" or a "chronological" way.

Traditional measures are based on a simplified understanding of ageing, with chronological age being the only parameter considered. However, a number of scholars have recently argued that these indicators are too limited (Denton and Spenser 2000; Sanderson and Scherbov 2008, 2010). According to these authors, the age of an individual is not commensurable across different historical points in time. For example, a Greenlander who was aged 60 in 1900 had far fewer remaining years of life than his 60 -year-old descendant living today due differences in life expectancy (LE), health, and well-being during these two periods. These observations have led scholars to rethink how we measure age and ageing, with new metrics of ageing being introduced by Scherbov and Sanderson (2008). These new measures incorporate changes in people's characteristics beyond traditional chronological age, such as prospective age and changes in remaining life expectancy (RLE).

If we are considering purely chronological age, we know that a person who had reached the age of, say, 50 in 1900 or in 2015 had lived for precisely 50 years. If, however, we are considering prospective age, we cannot assume that the person's remaining number of years was constant between 1900 and 2015, given that today's $\mathrm{LE}$ at older ages is longer and is continually increasing. For a more detailed explanation of prospective age, we refer the reader to the publications of Sanderson and Scherbov (2008, 2013, 2016), who originated and developed the concept of prospective ageing.

Here we give one explanatory example linked to the North Atlantic context. In 1900, a 50-year-old Icelandic woman had 20.4 remaining years to live, while a 50year-old Icelandic man had 17.4 remaining years to live (Table 1 ). We estimated new prospective ages in 1950, 2000, and 2015 based on these RLEs from 1900. Between 1900 and 2015, the prospective ages of 50-year-old Icelandic men and women rose by around 15 years. Thus, in Iceland in 2015, 66-year-old women and 67-year-old men were "the new 50-year-olds" relative to their forebears of 1900. This substantial 
Table 1:

The calculated prospective ages in 1950, 2000, and 2015 at which remaining life expectancy (RLE) is the same as at the age of 50 in 1900, by sex, standard year Iceland 1900

\begin{tabular}{lcc}
\hline & Males & Females \\
\hline RLE at the age of 50 in 1900 & 17.4 & 20.4 \\
1950 & 60.3 & 59.8 \\
2000 & 65.4 & 64.0 \\
2015 & 67.4 & 66.1 \\
\hline
\end{tabular}

Source: Data on life expectancies at different ages were obtained from the Human Mortality Database and Statistics Iceland (for the year 2015). Prospective ages are calculated by the authors.

growth in RLE cannot be ignored when population ageing is measured, as failing to take prospective age into account may give a false picture of how old the society in question was in the past, is in the present, and will be in the future.

The prospective indicators in this analysis include the share of people with an RLE of 15 years or less (Prop RLE 15), the prospective median age (PMA), the prospective ageing index (PAI), and the prospective old-age dependency ratio (POADR). The PMA is derived from the life table in which the remaining LE is the same as the MA in the reference year: in this study, the life table refers to Iceland in 2005. The Prop RLE 15 is calculated as the number of people in age groups in which the RLE is 15 years or less, divided by the total population. The POADR makes the share of people older than the RLE of 15 years or less the old-age threshold in the numerator, which is divided by the number of people between the ages of 15 and the old-age threshold. The PAI relates the number of people older than RLE 15 or less to the number of children between the ages of zero and 14. More information on the computation techniques used for prospective indicators can be found in the publications of Sanderson and Scherbov from 2008 to 2016 (see references).

Prospective indices consider changes in longevity, and refer to a floating number of prospective years to live, as denominated in Table 1, instead of a constant number of chronological years. For the chronological indices, a 60-year age threshold is used in the calculations. It may sound artificial to consider all people older than age 60 as old. This population group is highly heterogeneous and is largely still productive in labour market terms. Moreover, retirement ages can be well above 60; in Iceland, for example, the official retirement age is 67 (Hansen et al. 2012, 18). However, this analysis focuses on demographics rather than on labour force analysis, and 60 is chosen as a reasonable basis for cross-regional comparisons. As the age threshold of 60 is used in a pan-Arctic study on ageing (data available in Emelyanova [2015]), relying on this threshold also facilitates numerical comparisons on ageing between the North Atlantic and the rest of the Arctic region. Regardless of whether we use 
an age threshold of 60 or 65 , the trends in ageing dynamics measured will show the same pattern.

\section{Results and discussion}

The North Atlantic region has a population that is already out of balance in many respects (Rauhut et al. 2008; Hansen et al. 2011, 2012a, 2012b; Roto et al. 2014). The complex interrelations of migration, natality, death rates, and family choices suggest that the size and the characteristics of this population are changing dramatically, and that policy regulation is needed. Without entering into a broader discussion of these issues, it is important that we mention several intraregional demographic features of the area under study: (i) North Atlantic reproduction rates are comparatively high, but have been declining in recent decades due to changes in mortality and fertility; and (ii) migration heavily distorts the birth-death balance, and leads to particularly intense societal ageing trends in rural and remote areas. These areas are ageing rapidly because large shares of young people (notably young women) leave to find employment, marry, and further their education in the capitals and larger cities of the North Atlantic, including Nuuk, Reykjavik, Akureyri, and Tórshavn. Below, we identify the scope of ageing heterogeneity and cross-territorial trends for recent decades in the North Atlantic setting.

\subsection{Patterns of longevity at a later age}

Longevity is a powerful driver of population ageing. Greenland's average LE was lower than that of Iceland and the Faroe Islands at the beginning of the 1980s, which caused a noticeable cross-territorial gap. In 2015, the populations of Iceland and the Faroe Islands had a life expectancy of 82 years, or eight years more than the population of Greenland (Statistics Iceland 2016; Statistics Faroe Islands 2016; Statistics Greenland 2016). In fact, Icelandic men have a LE at birth (81 years) that is among the highest in the world, and that is two years higher than the LE of Faroese men. The life expectancies of Icelandic females and males have been steadily converging due to male "leapfrogging" (Statistics Iceland 2016).

Alternative measures of ageing use the expected time to death derived from life tables. Lutz and colleagues have argued that the traditional LE at older ages should be complemented with estimates of how many people with an RLE of 15 years or less there are in the population, as these people are more likely to be dependent on public services than the population aged 60 or $65+$ (Lutz et al. 2008). While life expectancy has increased across the region, it has grown to varying degrees at different ages (Table 2). Longevity has clearly risen more slowly at later ages than at birth. For example, an average increase of 5-8 years in LE at birth translates into an average increase of just 1-4 years at the ages at which RLE is equal to 15 (Age RLE 15). In recent decades, the growth in the age at which RLE 15 is reached has 
been insignificant among Greenlandic men and women, but has been particularly strong in the Faroe Islands due to recent increases in longevity, and possibly due to improvements in the national health care system.

Another indicator that directly reflects changes in longevity is the median age (MA). If we compare the MA standardised for expected RLE (prospective) with traditional (retrospective) LE, we see that the MA provides more accurate estimates of changes in the length of a population's life and health. The MA in the North Atlantic has been gradually rising for both sexes, and has increased by almost 10 years over the past three decades. In 2013, the MA of the region's population reached 36 years, or four years lower than the Danish MA. In 1980, by contrast, the MA of the North Atlantic population was eight years lower than the Danish MA. While the cross-territorial differences have diminished, the gender gap in the MA has been consistent throughout the period, with women having an MA that was 2-3 years higher than that of men in all territories.

The median age has increased due to two trends that have intensified since the end of the 1960s: decreasing birth rates and increasing LE. While the birth rates in the North Atlantic have declined slightly less than in the Nordic region, and considerably less than elsewhere in Europe, these decreases have still been pronounced. Whereas the TFR (total fertility rate) in Iceland rose as high as four in 1964, it had fallen to 1.8 by 2015 (Statistics Iceland 2016). In Greenland, the TFR decreased from 2.7 in 1970 to 2.0 in 2015 (Statistics Greenland 2016). In the Faroe Islands, the TFR declined from 3.4 to 2.4 over the same period (Statistics Faroe Islands 2016). Deviations from the levels of fertility attained will also have large effects on population change. According to United Nations forecasts, Iceland and the Faroe Islands will have TFRs of 1.8 in 2050; while according to the authors' projections, the TFR in Greenland will grow to 2.2 by 2050 .

Future birth rates could also be affected by national policies, and, to some extent, by abortion rights. In Greenland, women have full access to abortion services; while in the Faroe Islands and Iceland, access to abortion is restricted to certain cases of medical or social necessity. The abortion rate in Greenland grew substantially over several decades prior to the 2000s, whereas in the other two territories, where abortions are restricted, the rates have been low (Johnston 2016). However, there have been no drastic changes in abortion rates in the recent past, possibly because more information is being made available about contraception and family planning. The question of why these policies have affected fertility rates at the local level needs to be further investigated. It has been suggested that the North Atlantic is entering the final stage of the Demographic Transition model (from high to low births and deaths). Additional changes in fertility at the local level could be caused by higher educational attainment, financial uncertainties and crises in local economies, intense urbanisation, the labour market behaviour of higher educated women, and other local factors.

Conventional median ages have been compared to PMAs, which are calculated on the basis of period life tables and adjusted to the respective changes in life expectancy. Just as economic analysts compute the outputs of various countries 


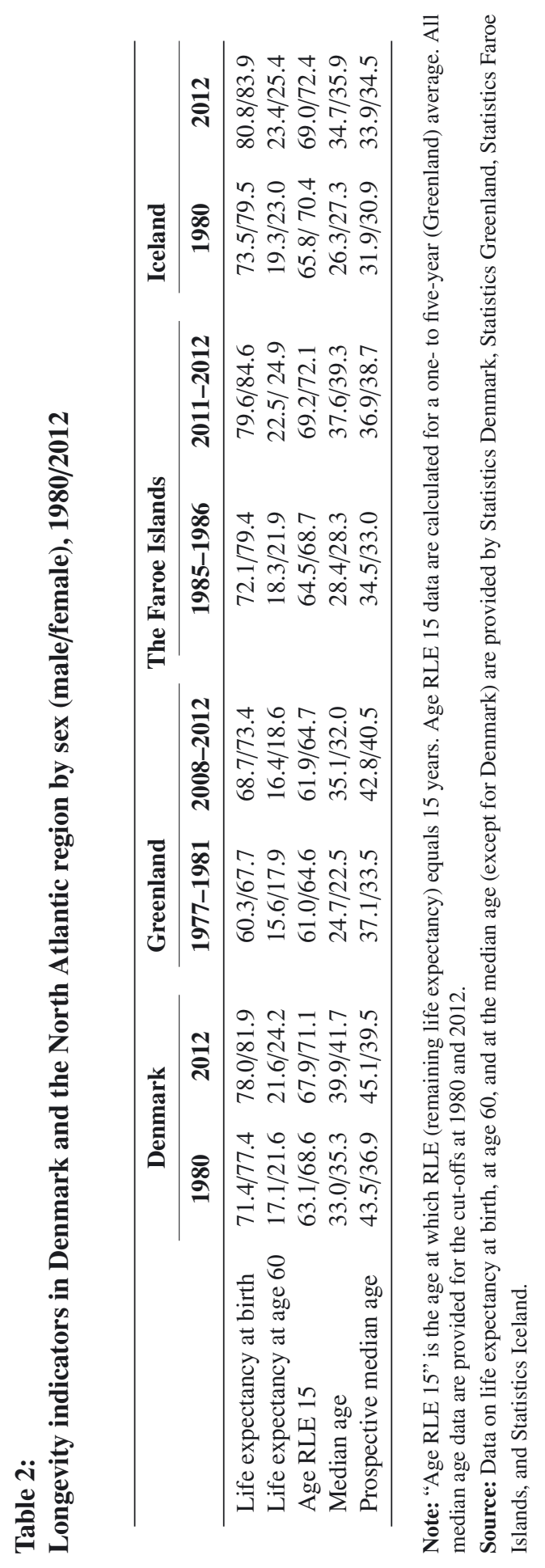


using a standard currency, demographers calculate the PMAs of various territories using a common life table as a reference (see Sanderson and Scherbov 2008). In our study, we matched the MA to one standard life table: that is, the life table that refers to Iceland in 2005. We identified the ages at which the RLE was the same as at the MA in the indicated year for the same territory. Appendix 1 contains the resulting calculations for the PMAs. A different picture of ageing emerged when we applied this technique: while the PMA was growing, it was increasing at half the pace of the MA: over three decades, the PMA rose 3-4 years (males-females), while a commonly used MA increased 8-9 years. Across the region, the PMA grew most rapidly in Greenland, where it increased 6.4 years in the 1980-2010 period. Over the same period, the PMA grew only 2.5 years in the Faroe Islands and in Iceland.

\subsection{Age structure}

In the North Atlantic, cohort effects as well as socioeconomic particularities continue to have a substantial impact on the development of the population age structure. One concern is that an ageing population may lead to increased demand for public services. Small island communities of the North Atlantic face many challenges related to ageing. For instance, because they have difficulties recruiting qualified specialists in gerontology, geriatrics, and other medical specialties, patients are sometimes sent for treatment to Denmark or Iceland. In addition to being expensive, this system can impose hardships on older people. Thus, further developments in local infrastructure and regional cooperation in the provision of medical care for the elderly are needed.

According to Gløersen et al. (2005: 64), demographic changes are "the most comprehensive synthetic indicator of economic and social dynamism", and have a big impact on age structure. The North Atlantic experienced strong population growth in the last century. At the beginning of the 20th century, approximately 100,000 people lived in the Faroe Islands, Greenland, and Iceland. Within one hundred years, the population of Greenland had increased more than fivefold, the population of Iceland had increased fourfold, and the population of the Faroe Islands had more than tripled. These growth rates are tremendous when compared with the general population declines that were occurring in Europe and in other regions of the Arctic. However, from the 1990s onwards, this growth trend reversed, and turned into a trend towards "thinning out societies" (Aasbrenn 1989).

Currently, the populations of the North Atlantic region have the lowest proportions of elderly people and the highest shares of children and young people in the Nordic country group. While Greenland has the youngest population by any measure (Foss and Juvkam 2005), its birth rates have been declining in the period studied. In Iceland, the share of young people in the population has also increased. Thus, compared with the rest of the Europe, the region has a relatively young labour force. 


\section{Figure 2:}

Danish and North Atlantic proportions of the population with a remaining life expectancy of 15 years or less (Prop RLE15-), sexes combined, (\%) of total population, 1980-2010

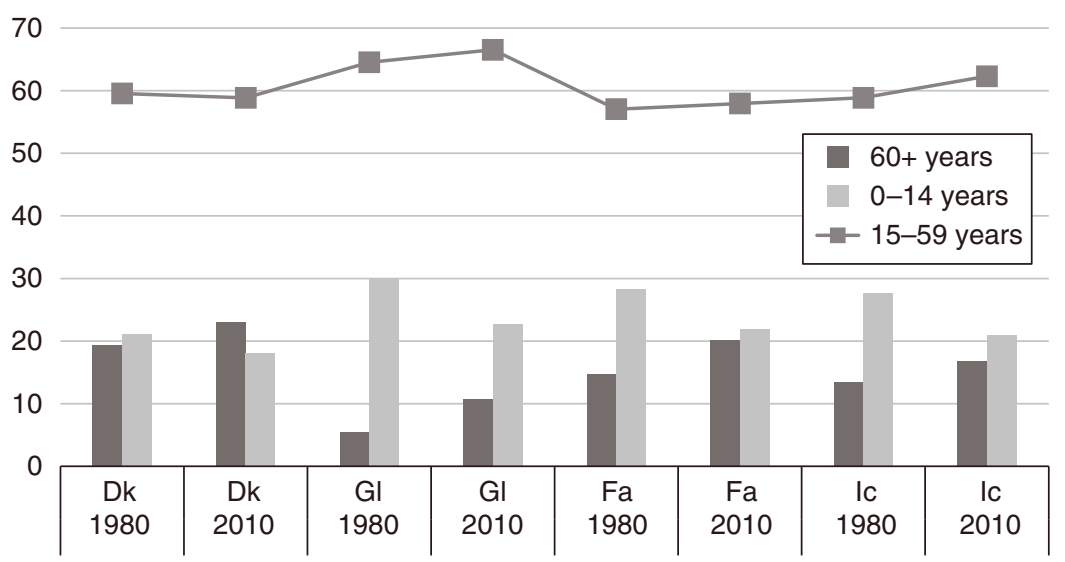

Note: Dk: Denmark, Gl: Greenland, Fa: the Faroe Islands, Ic: Iceland. The data are the authors' calculations based on population counts and mortality numbers provided by Statistics Denmark, Statistics Greenland, Statistics Faroe Islands, and Statistics Iceland.

When the changes in broader population age groups (youth, adults, and the elderly) are tracked, clear shifts can be seen over the last three decades (Figure 2). The shrinking number of children and teenagers is a direct result of the tendency among young people in the North Atlantic to have fewer children. Urbanisation plays a large role in this shift. As Hansen et al. (2012) observed, the more rural areas of the Faroe Islands are experiencing a greater reduction in the proportion of the young people in the population than the rural areas of Greenland. Greenland has experienced a similar decline in its capital region, whereas in Iceland, there has been a decrease in all parts of the country.

Because of the relative lack of educational and employment opportunities in the North Atlantic, migration is a significant accelerator of population ageing in the region, causing the shares of young and working-aged people in the population to shrink. Although the North Atlantic is remote and travel is expensive, the people are mobile (Hansen et al. 2011), in part because Nordic citizens are permitted to move freely within the Nordic region under regional labour and educational policies (Dustmann and Albrecht 2011). There is, however, a noticeable gender discrepancy in the numbers of young people emigrating from small settlements, as women are more likely than men to permanently leave their home island communities and the region itself (Rasmussen 2005), taking with them their labour skills and potential offspring. More women than men from Greenland, and to a lesser degree from the Faroe Islands, have moved to Denmark to enter into interethnic marriages with 
Danes. Some older people from Greenland and the Faroe Islands move to Denmark after retirement, which tends to increase the share of people aged 60+ in the Danish population. Figure 2 shows that Denmark had the largest share of people aged 60+ in the population in 1980 (19\%) and in $2010(23 \%)$.

Denmark also has the smallest share of children in the population. The North Atlantic regions used to perform better in this regard, and more data can be seen in Appendix 1. At the same time, an intense wave of out-migration of young people and children in recent years has caused the islands' populations to age even further. If we compare 1980 to 2010, we see that the proportion of working-aged (15-59) and older $(60+)$ people in the population increased by $0.9 \%$ and $5.5 \%$, respectively, in the Faroe Islands, by $2.1 \%$ and $5.3 \%$ in Greenland, and by $3.4 \%$ and $3.3 \%$ in Iceland.

\subsection{Proportion of older people}

Focusing specifically on the proportion of older people in the age structure, we see that the chronological age-based methods indicate that the sex balance has changed in recent years. From 1980 to 2013, the share of men aged 60+ in the population grew from $4.5 \%$ to $12 \%$ in Greenland. In Iceland, this share had reached $12 \%$ by the 1980s. The number of Icelandic men aged 60+ increased by almost one-third over this period. In 2013, the Faroe Islands had the highest share in the region of men aged $60+$ in the population $(20.6 \%)$. Among women aged $60+$, the fastest changes occurred in the Faroe Islands, where the share of older women in the population reached $23.2 \%$ in 2013 . The share of women aged $60+$ in the population reached somewhat lower values in Iceland (19\%) and in Greenland (11.3\%) in 2013. In Greenland, the shares of men and women aged 60+ were roughly the same in 1980, but by 2013, older men outnumbered older women. This is an unusual situation given that older women outnumber older men in most parts of the world. The explanations for this gender imbalance include the high rates of out-migration of women from the island since the beginning of the 1990s and the predominance of male-oriented employment sectors. Rauhut et al. (2008) also observed that the share of people aged $60+$ in the population is relatively low in Greenland due to the shorter LE and the fact that many pensioners choose to settle in Denmark.

The related Prop 60+ measure refers to the proportion of people considered old when the average remaining lifespan in their age group is less than 15 years. Figure 3 illustrates the evolution of Prop RLE 15 proportions in the 1980-2010 period. When we weight the RLE of all age groups with the proportions of people belonging to those age groups in the population, the dynamics of population ageing are altered. We see changes for both sexes: Prop RLE 15 declines slightly in every territory, except in Greenland due to its lower LE. At the end of the period, the differences between the North Atlantic territories diminish noticeably, and the ratios, including the OADRs, start to converge. Hence, the historical ageing trends look different than they did when we were using the conventional definition of elderly people. 
Figure 3:

Danish and North Atlantic proportions of the population with a remaining life expectancy of 15 years or less (Prop RLE 15) by sex, (\%) of total population (1980-2010)

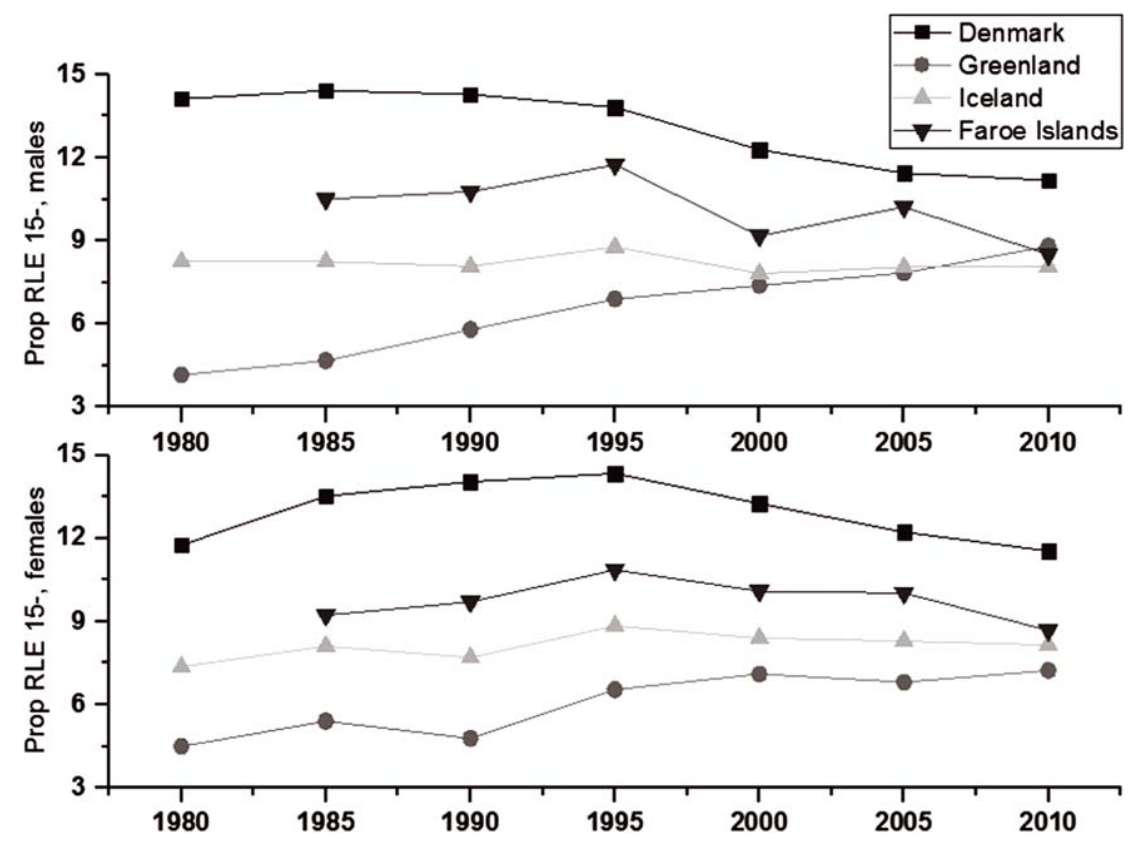

Note: The data are the authors' calculations based on population count and mortality numbers provided by Statistics Denmark, Statistics Greenland, Statistics Faroe Islands, and Statistics Iceland.

\subsection{Dependency ratios}

The old-age dependency ratio (OADR), a common measure of ageing, corresponds to the ratio between the number of older people and the total working-aged population (aged 15-59). The current OADRs were calculated based on the knowledge that the complementary measure, the young age dependency ratio, is higher in Iceland, Greenland, and the Faroe Islands than in other Nordic territories. For the middle-share ratios, there is, as mentioned above, an upwards trend in the migration of young, educated women to other economically prosperous areas and countries (Rasmussen 2011).

Over the study period, the highest OADR load for both sexes was in the Faroe Islands, followed by in Iceland. Greenland had the lowest OADR due to the relatively large share of young people in the age structure of its population. The speed of change of the ratio differed over the period, with the fastest growth occurring in the Faroe Islands, particularly among women. The OADR grew half 
as quickly in Greenland and in Iceland as in the Faroe Islands among women. Greenland's male population experienced relatively fast OADR growth. Topping the whole North Atlantic region was Denmark, where the indicator was two to three times higher than in Greenland.

Given this pronounced growth in old-age dependency, as measured conventionally, over just over three decades, local governments and stakeholders may raise concerns about the sustainability of current welfare systems. However, it must be taken into account that, as people age, they tend to gain healthy years, and thus do not automatically become a burden on the health care and social welfare systems after the age of 60 . These dependency ratios change when the prospective OADR is calculated, as both the numerator and the denominator are affected by the oldage threshold. In the prospective OADR, the old-age threshold is connected to the floating LE, rather than being set at age 60. Increases in the threshold age (RLE 15) reduce the number of people considered old, and hence increase the share of people of working age. Figure 4 illustrates that the dependency ratios are much lower using this approach than using the chronological approach. The POADRs for both sexes and in all areas increase less rapidly than when the traditional OADR is applied. Moreover, the figure shows that the POADR has been slowly decreasing in most of the North Atlantic since the 1990s, whereas the OADR has been growing.

By replacing the number of people aged 60 years or older in the calculations with the number of people older than the specific old-age threshold, we provide a new type of evidence regarding societal dependency in old age, adjusted to longevity and health transformations. This exercise showed a decrease in dependency in Denmark and the Faroe Islands for both sexes, and for males in Iceland. One exception is Greenland, where the POADR has been growing. This trend is related to the accelerating ageing and the relatively early stage of the health and demographic transition of the Inuit population ("natives born in Greenland" in Statistics Greenland) who made up $89 \%$ of the total population in Greenland in 2015 (Statistics Greenland 2016).

\subsection{Ageing indices}

It is important to address the ageing index (AI) when analysing changes in age structure, as it is greatly influenced by survival and fertility rates. The composite AI shows the interrelations between the old and the young age groups, and estimates how fast a population is ageing by calculating the number of people aged $60+$ for every 100 young people under age 15 (the elder-child ratio). Figure 5 shows that the AIs generally increased among the populations in the North Atlantic between 1980 and 2010. The Faroe Islands had the highest AI for both sexes, followed by Iceland, with Greenland lagging considerably behind. The AIs of the Faroe Islands and Iceland grew rapidly in recent years due to the sharp rise in the proportion of the population with higher education, which is an important factor in falling birth rates, among other things. When comparing chronological and prospective AIs, it is 


\section{Figure 4:}

Chronological and prospective old-age-based dependency ratios in Denmark and the North Atlantic region, sexes combined, 1980-2010
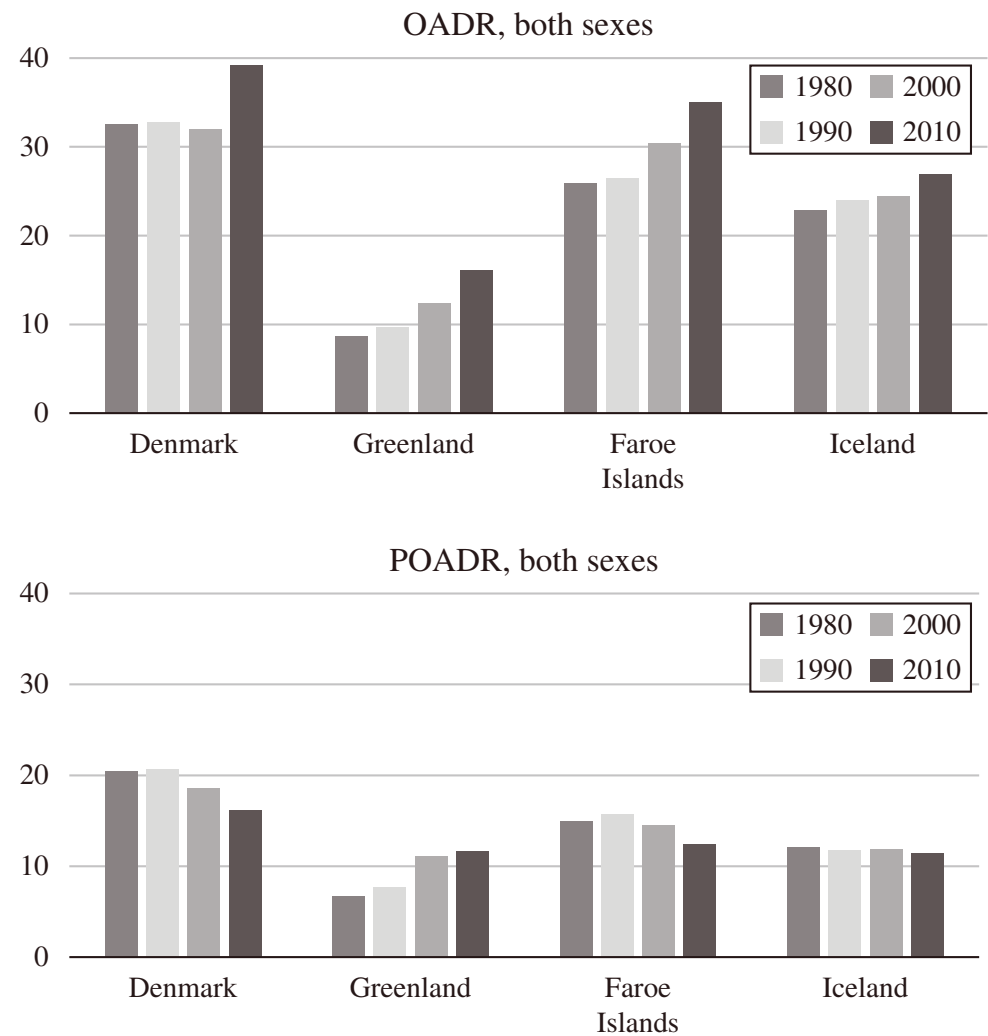

Note: OADR: Old-age dependence ratio, POADR: Prospective old-age dependency ratio. The data are the authors' calculations based on mortality numbers provided by Statistics Denmark, Statistics Greenland, Statistics Faroe Islands, and Statistics Iceland.

interesting to observe that the PAI values rose more slowly than the AI values, and that there were also some downwards trends, such as in the Faroese population after 1995. These developments led to a convergence (particularly among males) in the PAI rates by 2010 across the three North Atlantic territories (Figure 5).

\section{Conclusion}

The ageing variations across the North Atlantic considered in this study are determined by broad demographic drivers: 
Figure 5:

Chronological and prospective old-age-based ageing indices in Denmark and the North Atlantic region, sexes combined, 1980-2010
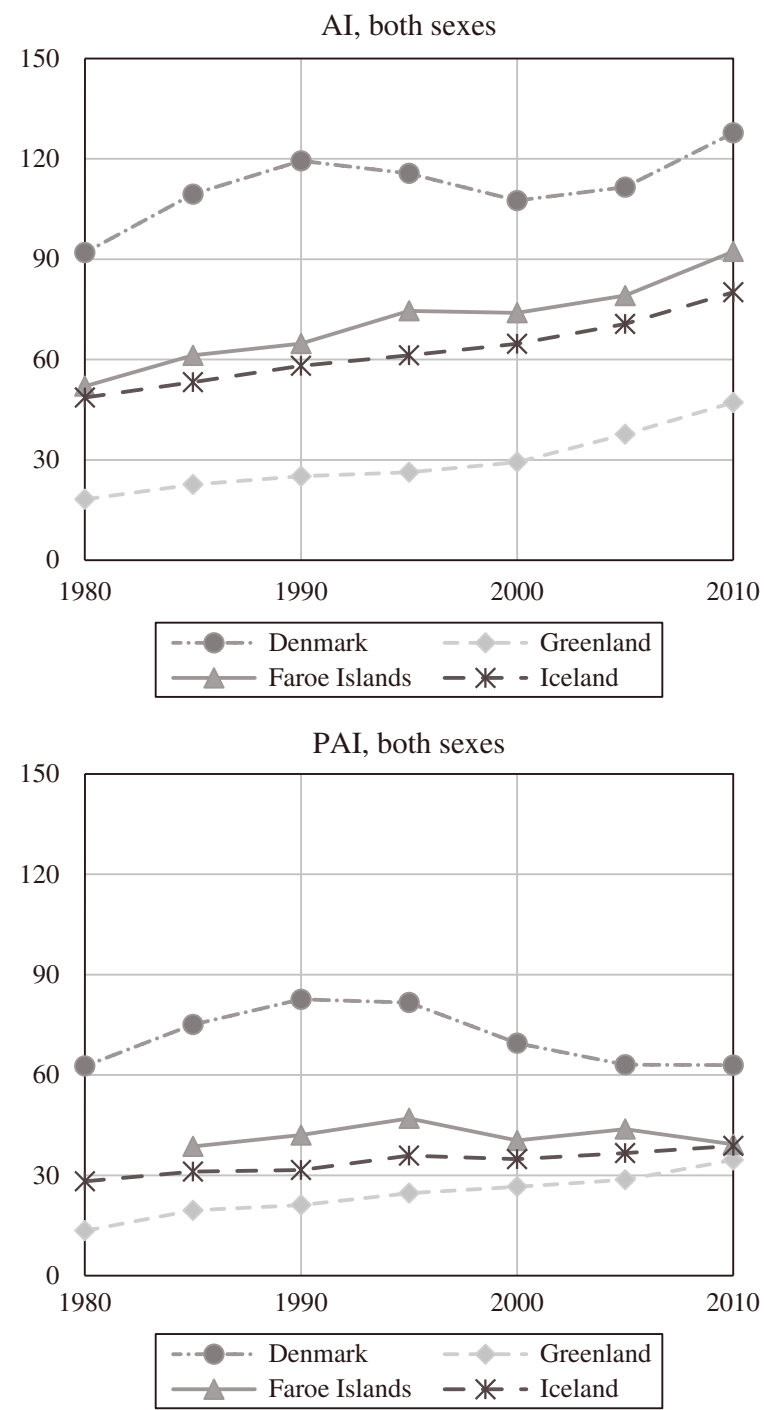

Note: AI: Ageing index, PAI: Prospective ageing index. The data are the authors' calculations based on population counts and mortality numbers provided by Statistics Denmark, Statistics Greenland, Statistics Faroe Islands, and Statistics Iceland.

- Iceland and the Faroe Islands have one of the highest life expectancies in the world (82 years in 2015) and the lowest mortality levels in the world, whereas life expectancy in Greenland lags eight years behind (74 years in 2015). 
- The TFR has historically been higher in the North Atlantic than in nearly every other country in Europe, but as was noted in the results and discussion sections, it has been falling since the end of the 1960s: i.e., the average TFR across the three territories declined from three in 1970 to two in 2015. This value is around the replacement level and above the Danish national average.

- A powerful ageing driver within this geography is the meaningful out-flow of college-bound youth (representing 15\% of youth emigration in the age group 20-24 in the Faroe Islands in 2015), and of educated people in older age groups, especially from rural areas (Statistics Faroe Islands 2016). This trend started to accelerate in the 2000s, and was accompanied by large waves of out-migration after the fishery/banking crises. In such conditions, ageing can exacerbate the challenges faced by rural and fishery communities, acting in concert with factors such as limited access to public services and transport, and decreasing income levels.

Following the study aims outlined in the introductory part of the paper, and based on the data summarised in Appendix 1, the results shed light on the oldest and the youngest, and the fastest and the slowest areas of ageing. The traditional measurements indicate that there has been an explicit upwards trend in ageing in all of the North Atlantic territories except in Denmark, where the MA and the OADR decreased in 1990-2000 and the AI decreased until 2010. In 2010 the most advanced ageing was found for the Faroese population, with Greenland lagging far behind. However, from 1980 to the present, Greenland (particularly the male population) has been experiencing the fastest ageing according to chronological measures, with the indices' values increasing two- to threefold. The trends in ageing in Greenland are also distinct in terms of sex differences, with older men outnumbering older women, which is rare worldwide. Meanwhile, the traditional indicators showed that Iceland has been ageing less rapidly, with its rates occupying a middle position between those of its two neighbours. Moreover, according to the chronological indices, the ageing rates in the North Atlantic territories have not been converging, but have instead been developing in parallel, while keeping the same ranking throughout the period.

The results of the prospective ageing indicators differed markedly from those of the chronological indicators. The prospective indicators showed that the ageing rates of the North Atlantic territories have been converging, and had reached almost the same degree of ageing by the 2010 observation, particularly among men. These findings diverge not just from those of traditional measurements of ageing dynamics, but from findings for some other regions of the Arctic, such as for the North American Arctic (Alaska and the Canadian North), where a high degree of cross-territorial divergence has been found (Emelyanova 2015). The ranking of the territories also changed. While the Faroe Islands had the highest chronological ageing rates, Greenland had the highest prospective estimates in 1980 and 2010 (e.g., PMAs). The prospective approach also showed a slower pace of ageing at several points in time. For Iceland and the Faroe Islands, this process even appeared to be 
reversed in the most recent decade, signifying a so-called population rejuvenation. A rejuvenation trend was found when the POADR rates (2000s) were applied to these two territories, and the Prop RLE 15 was shown to have declined for males in Iceland and in the Faroe Islands over the 1980-1990 period. Similar trends in the PAI, the PMA, and the Prop RLE 15 after the 2000s were found among Faroese women. Almost all of the indices of prospective ageing for Denmark were shown to be decreasing.

The future path of ageing in the North Atlantic communities needs to be continually monitored and forecasted, as smaller populations can experience greater fluctuations and more abrupt changes in terms of age structure and population size than larger populations. The way ageing is measured also needs to be taken into account, as we have shown for the case of the North Atlantic in this study. The prospective measurement of ageing indicates that societal ageing is not developing as quickly or as linearly as the chronological approach has shown; thus, our understanding of the consequences of ageing and our responses to this phenomenon may need to be reconsidered.

\section{References}

Aasbrenn, K 1989. Uttynningssamfunnet. Det demografisk uttynnede - men ikke avfolkede utkantsamfunn in. Tidskrift for samfunnsforskning 30(5/6): 509-519.

Danilova, R., E. Golubeva and A. Emelyanova 2011. Demographic aspects of the social safety of the elderly population in the Barents Euro-Arctic region. Advances in Gerontology 1(3): 195-202.

Denton, F. and B. Spencer 2000. Some demographic consequences of revising the definition of 'Old' to reflect future changes in life table probabilities. SEDAP Research Paper 2000-22. Hamilton, Canada: McMaster University.

Dustmann, C. and G. Albrecht 2011. Migration and education. Discussion Paper 201111. Norface Research Programme on Migration, Department of Economics. London: University College London.

Emelyanova, A. and A. Rautio 2012. Ageing population in the Barents Euro-Arctic region. Journal of European Geriatric Medicine 3(3): 167-173.

Emelyanova, A. and A. Rautio 2013. Perspectives for population ageing in the Russian North. Journal of Population Ageing 6(3): 161-187.

Emelyanova, A. 2015. Cross-regional analysis of population aging in the Arctic. Academic doctoral dissertation. Acta Universitatis Ouluensis D Medica 1326, Juvenes Print Tampere, 2015, pp. 1-94. http://herkules.oulu.fi/isbn9789526210049/isbn9789526210049. pdf, accessed on 23 August 2016.

Emelyanova, A. and A. Rautio 2016. Population diversification in demographics, health, and living environments: the Barents Region in review. Nordia Geographical Publications Yearbook 2016. Forthcoming.

Foss, O. and D. Juvkam 2005. Patterns of demographic ageing and related aspects in the northern peripheries. Nordregio Report 2005-2. Stockholm: Nordregio. 
Gløersen, E., A. Dubois, A. Copus and C. Schürmann 2005. Northern peripheral, sparsely populated regions in the European Union. Nordregio Report 2005-04. Stockholm: Nordregio.

Golubeva, E. and R. Danilova 2011. Improving the social safety of elderly population in the system of social work on sparsely populated areas of European North of Russia. Medico-Biological and Socio-Psychological Problems of Safety in Emergency Situations 4: 85-88.

Hamilton, L. and A. Mitiguy 2009. Visualizing Population Dynamics of Alaska's Arctic Communities. Arctic 64(4): 393-398.

Hansen, K., R. Rasmussen and J. Roto 2011. Demography in the Nordic countries - a synthesis report. Nordregio Working Paper 2011-09. Stockholm: Nordregio.

Hansen, K., R. Rasmussen, J. Roto and C. Fredricsson 2012a. Megatrends in the Arctic - new inspiration into current policy strategies. Nordregio Working Paper 2012-08. Stockholm: Nordregio.

Hansen, K., R. Rasmussen and J. Roto 2012b. Nordic perspectives on demography - a background report for the project on coastal societies and demography. Nordregio Working Paper 2012-12. Stockholm: Nordregio.

Johnston, R. 2016. Historical abortion statistics. http://www.johnstonsarchive.net/policy/ abortion/index.html, accessed on 27 September 2016.

Larsen, J. N. and G. Fondahl, eds 2014. Arctic human development report. Regional processes and global linkages. Copenhagen: Nordic Council of Ministers.

Leeson, G. 2002. The changing face of the population in Europe. Nordregio Working Paper 2002-02. Stockholm: Nordregio.

Lewis, J. 2013. The future of successful ageing in Alaska. International Journal of Circumpolar Health. doi.org/10.3402/ijch.v72i0.21186.

Lutz, W., W. Sanderson and S. Scherbov 2008. The coming acceleration of global population ageing. Nature 451: 716-719.

Moore, E. and M. Pacey 2004. Geographic Dimensions of Ageing in Canada, 1991-2001. Canadian Journal on Ageing/La Revue Canadienne du Vieillissement 23(suppl.): 5-21.

Hörnström, L. and J. Roto 2013. A Nordic 'Agequake'? Population Ageing in Nordic Cities and Regions. Nordregio News Issue 2013-03, Stockholm: Nordregio. http://www.nordregio.se/en/Metameny/Nordregio-News/2013/Nordic-PopulationAgeing-Challenge-and-Opportunity/Context/, accessed on 24 August 2016.

Nummela, O., M. Seppänen and A. Uutela 2011. The effect of loneliness and change in loneliness on self-rated health (SRH): a longitudinal study among ageing people. Archives of Gerontology and Geriatrics 53(2): 163-167.

Rasmussen, R. 2005. Analysis of hunters and fishermen in Greenland. Grønlands Hjemmestyre - Direktoratet for Fangst og Fiskeri og NORS - Nordatlantiske Regionalstudier. Roskilde: Roskilde Universitets Center.

Rasmussen, R., ed. 2011. Megatrends. Copenhagen: TemaNord, Nordic Council of Ministers.

Rauhut, D., R. Rasmussen, J. Roto, P. Francke and S. Östberg 2008. The demographic challenge to the Nordic countries. Nordregio Working Paper 2008-01. Stockholm: Nordregio.

Roto, J., J. Grunfelder and L. Rispling, eds. 2014. State of the Nordic region 2013. Stockholm: Nordregio. 
Roto, J. and R. Rasmussen 40 years of population change in West Norden. http://www. nordregio.se/Metameny/About-Nordregio/Journal-of-Nordregio/Journal-of-Nordregio2010/Journal-of-Nordregio-no-3-2010/40-years-of-population-change-in-West-Norden/, accessed on 24 August 2016.

Sanderson, W. and S. Scherbov 2008. Rethinking age and ageing. Population Bulletin 63(4): $1-20$.

Sanderson, W. and S. Scherbov 2010. Remeasuring Ageing. Science 329(5997): 1287-1288.

Sanderson, W. and S. Scherbov 2013. The characteristics approach to the measurement of population ageing. Population and Development Review 39(4): 673-685.

Scherbov, S. and W. Sanderson 2016. New approaches to the conceptualization and measurement of age and aging. Journal of Aging and Health 28(7): 1159-1177, accessed on 16 December 2016.

Statistics Faroe Islands 2016. http://www.hagstova.fo/en, accessed on 23 August 2016.

Statistics Greenland 2016. http://www.stat.gl/default.asp?lang=en, accessed on 23 August 2016.

Statistics Iceland 2016. http://www.statice.is/, accessed on 23 August 2016.

United Nations. 2015. World Population Ageing 1950-2050. New York: Population Division DESA. (ST/ESA/SER.A/390). http://www.un.org/en/development/desa/population/ publications/pdf/ageing/WPA2015_Report.pdf, accessed on 16 December 2016.

Wilson, D., J. Osei-Waree, J. Hewitt and A. Broad 2012. Canadian provincial, territorial, and federal government aging policies: A systematic review. Advances in Aging Research 1(2): 38-46.

World Health Organization. 2011. Life expectancy ranking. http://www.who.int/gho/ mortality_burden_disease/life_tables/situation_trends_text/en/, accessed on 21 December 2013.

\section{Appendix}

Table A.1:

Population ageing indicators for the North Atlantic region by sex, 1980-2010

\begin{tabular}{|c|c|c|c|c|c|c|c|c|c|c|}
\hline Year & Sex & MA & PMA & $\begin{array}{l}\text { Prop } \\
60+\end{array}$ & $\begin{array}{c}\text { Prop } \\
\text { RLE 15 }\end{array}$ & $\begin{array}{c}\text { OADR } \\
\times 100\end{array}$ & $\begin{array}{c}\text { POADR } \\
\times 100\end{array}$ & $\begin{array}{c}\text { AI } \\
\times 100\end{array}$ & $\begin{array}{c}\text { PAI } \\
\times 100\end{array}$ & Age 15 \\
\hline \multicolumn{11}{|c|}{ Greenland } \\
\hline 1980 & Males & 24.72 & 37.13 & 4.51 & 4.17 & 6.76 & 6.14 & 15.67 & 13.32 & 61.02 \\
\hline 1990 & & 28.53 & 40.49 & 5.45 & 5.81 & 7.74 & 8.26 & 22.60 & 24.42 & 59.23 \\
\hline 2000 & & 32.56 & 42.53 & 7.34 & 7.40 & 10.96 & 11.09 & 28.52 & 28.54 & 59.74 \\
\hline 2010 & & 35.08 & 42.84 & 10.85 & 8.80 & 16.12 & 12.78 & 49.71 & 39.45 & 61.90 \\
\hline 1980 & Females & 22.52 & 33.51 & 6.54 & 4.50 & 10.55 & 7.22 & 20.74 & 13.55 & 64.63 \\
\hline 1990 & & 26.81 & 36.97 & 7.54 & 4.78 & 11.59 & 7.00 & 27.59 & 17.83 & 64.73 \\
\hline 2000 & & 29.59 & 41.69 & 8.66 & 7.10 & 13.84 & 11.09 & 30.13 & 24.64 & 62.54 \\
\hline 2010 & & 32.01 & 40.52 & 10.59 & 7.23 & 16.12 & 10.57 & 44.61 & 29.73 & 64.68 \\
\hline
\end{tabular}


Table A.1:

Continued

\begin{tabular}{|c|c|c|c|c|c|c|c|c|c|c|}
\hline Year & Sex & MA & PMA & $\begin{array}{c}\text { Prop } \\
60+\end{array}$ & $\begin{array}{c}\text { Prop } \\
\text { RLE 15 }\end{array}$ & $\begin{array}{c}\text { OADR } \\
\times 100\end{array}$ & $\begin{array}{c}\text { POADR } \\
\times 100\end{array}$ & $\begin{array}{c}\text { AI } \\
\times 100\end{array}$ & $\begin{array}{c}\text { PAI } \\
\times 100\end{array}$ & Age 15 \\
\hline \multicolumn{11}{|c|}{ Iceland } \\
\hline 1980 & Males & 26.30 & 31.95 & 12.24 & 8.25 & 20.53 & 12.98 & 43.51 & 29.34 & 65.80 \\
\hline 1990 & & 29.38 & 32.52 & 13.26 & 8.08 & 21.63 & 12.16 & 52.11 & 31.77 & 66.89 \\
\hline 2000 & & 32.13 & 33.12 & 13.83 & 7.83 & 22.16 & 11.45 & 58.12 & 32.90 & 68.84 \\
\hline 2010 & & 34.27 & 33.92 & 15.73 & 8.07 & 24.94 & 11.41 & 74.12 & 38.03 & 68.99 \\
\hline 1980 & Females & 27.34 & 30.94 & 14.63 & 7.36 & 25.17 & 11.25 & 53.74 & 27.03 & 70.41 \\
\hline 1990 & & 30.25 & 32.69 & 15.74 & 7.70 & 26.36 & 11.37 & 64.09 & 31.37 & 70.85 \\
\hline 2000 & & 32.48 & 34.97 & 16.27 & 8.41 & 26.73 & 12.23 & 71.20 & 36.78 & 71.06 \\
\hline 2010 & & 35.31 & 34.54 & 17.78 & 8.15 & 28.87 & 11.45 & 86.12 & 39.50 & 72.39 \\
\hline \multicolumn{11}{|c|}{$\begin{array}{l}\text { The Faroe } \\
\text { Islands }\end{array}$} \\
\hline 1985 & Males & 28.39 & 34.54 & 13.70 & 10.50 & 23.48 & 16.40 & 49.05 & 41.32 & 64.51 \\
\hline 1990 & & 30.39 & 35.46 & 14.04 & 10.78 & 22.76 & 16.60 & 57.75 & 44.34 & 64.24 \\
\hline 2000 & & 33.96 & 35.34 & 15.73 & 9.18 & 25.88 & 13.63 & 67.05 & 39.13 & 68.17 \\
\hline 2010 & & 36.71 & 36.63 & 18.85 & 8.50 & 31.70 & 12.18 & 87.02 & 39.25 & 70.00 \\
\hline 1985 & Females & 28.30 & 33.02 & 15.74 & 9.23 & 28.28 & 14.17 & 54.97 & 35.94 & 68.74 \\
\hline 1990 & & 31.06 & 33.74 & 17.53 & 9.71 & 30.21 & 14.75 & 71.76 & 39.75 & 69.22 \\
\hline 2000 & & 35.15 & 35.41 & 19.58 & 10.09 & 34.84 & 15.37 & 80.85 & 41.68 & 72.14 \\
\hline 2010 & & 38.18 & 35.34 & 21.58 & 8.68 & 38.32 & 12.55 & 97.58 & 39.26 & 74.46 \\
\hline \multicolumn{11}{|c|}{ Denmark } \\
\hline 1980 & Males & 33.00 & 43.51 & 17.16 & 14.12 & 28.14 & 21.89 & 78.40 & 66.17 & 63.12 \\
\hline 1990 & & 35.71 & 45.64 & 17.74 & 14.28 & 27.51 & 21.02 & 99.65 & 80.21 & 63.69 \\
\hline 2000 & & 37.23 & 45.23 & 17.34 & 12.29 & 27.29 & 17.91 & 90.76 & 64.29 & 65.25 \\
\hline 2010 & & 39.60 & 45.09 & 21.33 & 11.19 & 35.57 & 15.96 & 114.07 & 59.84 & 67.89 \\
\hline 1980 & Females & 35.26 & 36.89 & 21.48 & 11.75 & 36.94 & 19.05 & 105.50 & 59.18 & 68.65 \\
\hline 1990 & & 38.42 & 39.86 & 22.97 & 14.04 & 37.97 & 20.21 & 139.12 & 85.01 & 68.97 \\
\hline 2000 & & 39.39 & 39.78 & 22.03 & 13.25 & 36.56 & 19.19 & 124.28 & 74.75 & 69.50 \\
\hline 2010 & & 41.28 & 39.47 & 24.73 & 11.54 & 42.80 & 16.27 & 141.38 & 66.00 & 71.14 \\
\hline
\end{tabular}

Note: MA/PMA - (prospective) median age, PMA, refers to Iceland in 2005 as a reference year; Prop 60+ is the share of people aged 60 and older; Prop RLE 15 is the share of people with a remaining life expectancy of 15 years or less; OADR/POADR - (prospective) old-age dependency ratio; AI/PAI - (prospective) ageing index; Age 15 is the age at which the remaining life expectancy is equal to 15 . Greenland's data are provided for a five-year average only, as our calculations are based on mortality tables downloaded from Statbank of Statistics Greenland, provided for a five-year interval only. The table indicators refer to the periods of 1977-81, 1987-91, 1997-2001, and 2007-11. 
